\title{
La présentation de l'antigène aux lymphocytes $\boldsymbol{T}^{(1)}$
}

La reconnaissance des protéines antigéniques par les lymphocytes $T$ nécessite leur dégradation en peptides et l'association de ces peptides avec des molécules de classe I ou de classe II du complexe majeur d'histocompatibilité $(\mathbf{C M H})$. Les molécules de classe I sont spécialisées dans la présentation de protéines endogènes et lient les peptides dans le réticulum endoplasmique par leur chaîne lourde polymorphe. Après association avec la $\beta$-2 microglobuline, le complexe ainsi formé est exprimé de façon stable à la surface cellulaire. Lorsque la dégradation de la protéine se fait dans le cytoplasme, les peptides produits doivent être transportés dans le réticulum endoplasmique par des transporteurs dont les gènes seraient localisés dans le CMH. Les molécules de classe II sont spécialisées dans la présentation de protéines internalisées par endocytose et la liaison entre la molécule du CMH de classe II et un peptide se fait au niveau d'endosomes tardifs ou de pré-lysosomes. Les

\section{Chantal}

Rabourdin-Combe

Patrick Bertolino

Véronique

Calin-Laurens

Denis Gerlier

\section{ADRESSE}

C. Rabourdin-Combe : professeur à l'université Lyon I. P. Bertolino : boursier MRT. V. Calin-Laurens : agrégée préparaleur. D. Gerlier : chargé de recherche au Cnrs. ENSCnrs UMR 49, 46, allée d'Italie, 69364 Lyon Cedex 07, France.
(1) Cet article a fait l'objet d'une présentation orale à la 4e Journée Nationale d'Actualités en Immunologie, organisée par les Laboratoires Cassenne, à Paris, le 15 juin 1991. molécules de classe II sont transportées dans ce compartiment sous forme d'un complexe associant les deux chaînes $\alpha$ et $\beta$ avec la chaîne invariante. Après dégradation de cette dernière, la molécule de classe II se lie à un peptide; le complexe ainsi formé est exprimé à la surface cellulaire de manière stable et est reconnu par les lymphocytes $T$ spécifiques correspondants.

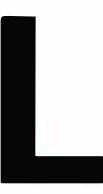

e système immunitaire des vertébrés supérieurs leur permet de neutraliser ou d'éliminer toute molécule ou toute cellule représentant un danger pour l'organisme. Les lymphocytes $\mathrm{T}$ et $\mathrm{B}$ du système immunitaire jouent un rôle primordial dans le maintien de l'intégrité d'un organisme car ils expriment des récepteurs spécifiques (récepteurs d'antigène) qui leur permettent de reconnaître l'ensemble des molécules présentes chez un individu. La discrimination entre le soi et le non-soi résulte de l'élimination des clones lymphocytaires autoréactifs et/ou de la suppression de leur activité chez l'individu adulte. Alors que les récepteurs d'antigène des cellules $B$, ou anticorps (Ac), ne reconnaissent que l'antigène $(\mathrm{Ag})$, les récepteurs d'antigène exprimés à la surface des lymphocytes $T$, ou récepteurs $T$ $(\mathrm{T} \mathrm{CR})$, reconnaissent une partie de l'antigène associée à une molécule codée par le complexe majeur d'histocompatibilité ( $\mathrm{CMH}$ ) de classe I ou de classe II. Après sa prise en charge par une cellule, appelée cellule présentatrice de l'antigène (CPAg), l'antigène doit subir un apprêtement (processing) avant d'être présenté aux lymphocytes $\mathrm{T}$. L'apprêtement de l'antigène nécessite un métabolisme cellulaire actif [1] et 

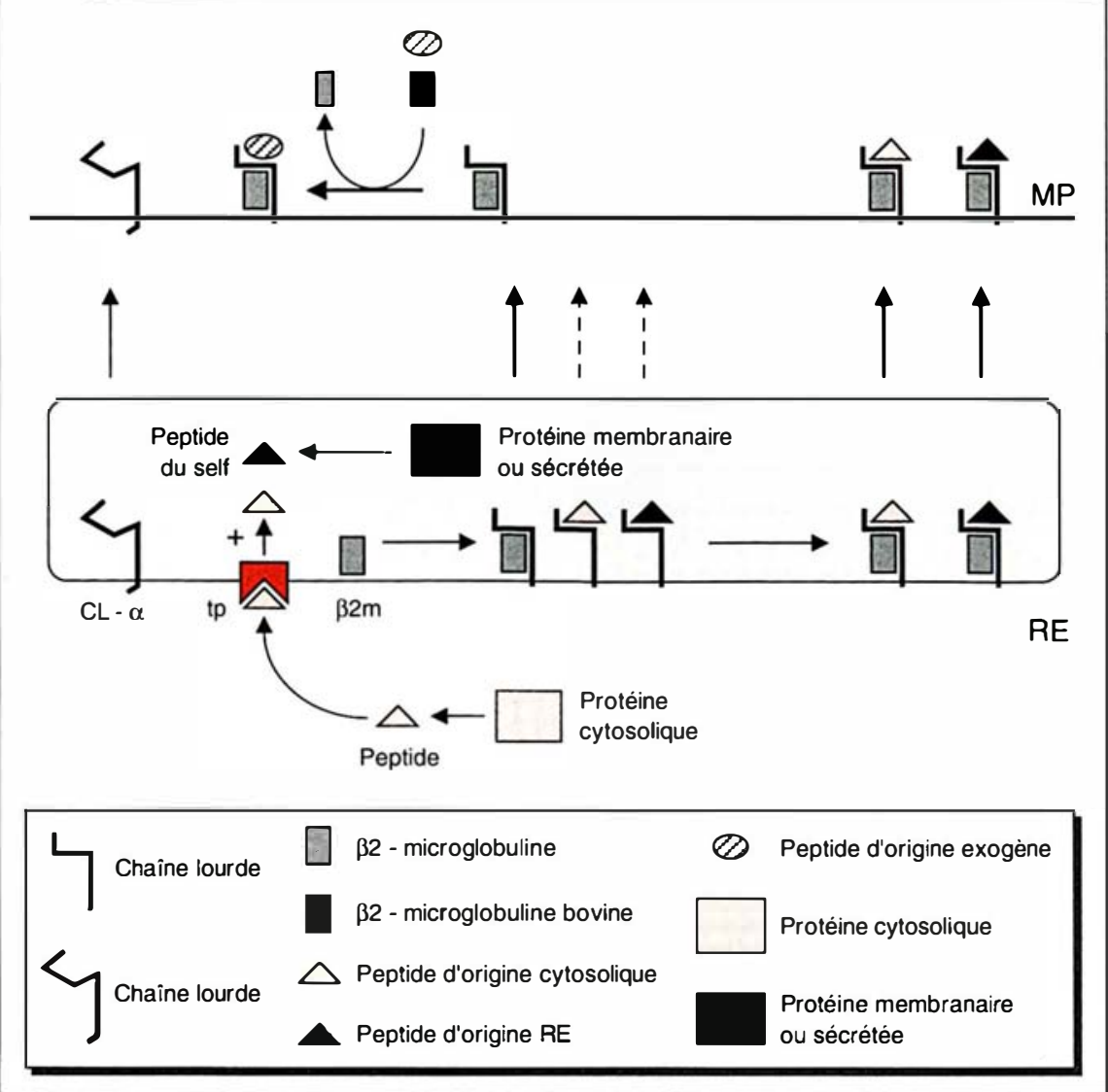

Figure 1. Schéma de la biosynthèse des molécules du CMH de classe I. La chaîne lourde $\alpha$ (CL- $\alpha$ ) s'associerait avec la $\beta 2$-microglobuline ( $\beta 2-m$ ) (ou à un peptide ?) (triangles) au niveau du réticulum endoplasmique (RE) pour former un complexe intermédiaire $\alpha / \beta 2-m$ (ou $\alpha /$ peptide ?). La liaison ligand/chaîne lourde $\alpha$ induirait un changement conformationnel de cette dernière. Les complexes $\alpha / \beta 2-m$ migreraient à la surface cellulaire et seraient instables à $37^{\circ} \mathrm{C} ; \mathrm{MP}$ : membrane plasmique ; leur dissociation permettrait un échange de la $\beta 2-m$ endogène (rectangles gris) avec de la $\beta 2-m$ bovine (rectangles noirs) (présente dans le sérum de veau fœtal) ainsi que la fixation $d^{\prime}$ 'un peptide $d^{\prime}$ 'origine exogène provenant du milieu de culture. Dans le RE, le complexe $\alpha / \beta 2-\mathrm{m} /$ peptide, stable à $37^{\circ} \mathrm{C}$, migre directement à la surface cellulaire, et peut être reconnu par une cellule $T$. Les peptides présents dans le RE proviennent soit de la dégradation de protéines cytosoliques (grand rectangle rose) soit de protéines membranaires ou sécrétées dont une partie pourrait être dégradée au cours de leur mutation dans le RE (grand rectangle noir). Les peptides engendrés dans le cytosol seraient transportés dans le RE par l'intermédiaire de transporteurs de peptides (tp).

comporte les étapes suivantes : une protéolyse en peptides, l'association de certains de ces peptides à des molécules du $\mathrm{CMH}$ et l'expression à la membrane de la CPAg des complexes peptide-molécule du $\mathrm{CMH}$.

\section{Les deux voies de présentation de l'antigène}

La reconnaissance de ces complexes peptide-molécule du CMH, via le $\mathrm{TcR}$ de cellules $\mathrm{T}$ spécifiques, con$m / s n^{\circ} 7$, vol. 7, septembre 91
Dans ce contexte, il est important de connaître le(s) mécanisme(s) qui condui(sen)t à l'association préférentielle d'un peptide avec l'une des deux classes de molécules du CMH. La compilation des résultats expérimentaux montre que le lieu de dégradation de l'antigène et la différence qui existe entre les voies de biosynthèse des molécules du CMH de classe I et de classe II (voir plus loin) sont à l'origine de cette association préférentielle. En effet, l'inhibition par la bréfeldine A, produit qui bloque la sortie des protéines du réticulum endoplasmique, de la présentation de l'antigène par les molécules de classe I et de classe II [2, 3] souligne l'importance des voies de biosynthèse dans les phénomènes de présentation. De plus, l'utilisation d'agents chimiques (chloroquine ou base faible) qui augmentent le $\mathrm{pH}$ des endosomes et des lysosomes a montré l'importance de ces compartiments pour la présentation de l'antigène par les molécules de classe II [4].

\section{Formation des complexes peptide-CMH de classe I}

Les molécules de classe I sont exprimées à la surface de presque toutes les cellules. Elles sont constituées de deux chaînes : une chaîne lourde polymorphe de $44 \mathrm{kDa}$ comportant trois domaines extracellulaires et une chaîne peu polymorphe de $15 \mathrm{kDa}$, appelée $\beta-2$ microglobuline $(\beta-2 \mathrm{~m})$. $\mathrm{La}$ cristallisation du fragment extracytoplasmique solubilisé de deux molécules de classe I humaines révèle, au niveau des deux domaines externes, une structure très particulière formée d'une plateforme de huit brins $\beta$ surmontée de deux hélices $\alpha$ [5]. La présence d'une densité électronique non identifiée à l'intérieur de la niche ainsi formée suggère la présence d'un matériel (peptide(s) ?) hétérogène. La dimension de la niche est compatible avec la fixation d'un peptide long de 6 à 20 résidus. Les chaînes lourdes sont synthétisées dans le réticulum endoplasmique en présence d'un grand excès de $\beta-2 \mathrm{~m}$ et sont exprimées, après environ 30 minutes, à la surface cellulaire sous une forme reconnaissable par un TcR. L'utilisation de mutants cellulaires $[6,7]$ et de nombreuses études 


\section{RÉFÉRENCES}

1. Shimonkevitz R, Kappler J, Marrack P, Grey $H$. Antigen recognition by H-2-restricted T-cells. I. Cell-free antigen processing. J Exp Med 1983 ; 158 : 303-16.

2. Ziegler HK, Unanue ER. Decrease in macrophage antigen catabolism caused by ammonia and chloroquine is associated with inhibition of antigen presentation to $\mathrm{T}$-cells. Proc Natl Acad Sci USA 1982 ; 79 : 175-8.

3. Nuchtern JG, Bonifacino JS, Biddison WE, Klausner RD. Bref eldin A implicates egress from endoplasmic reticulum in class I restricted antigen presentation. Nature $1989 ; 339: 223-5$.

4. Adorini L, Ulrich SJ, Appela E, Fuchs S. Inhibition by brefeldin A of presentation of exogenous protein antigens to MHC class II-restricted T-cells. Nature $1990 ; 346: 63-6$.

5. Bjorkman PJ. Structure, function, and diversity of class I major histocompatibility complex molecules. Ann Rev Biochem 1990 59 : 253-88.

6. Townsend A, Ohlen C, Bastin J, Ljunggren HG, Foster L, Karre K. Association of class I major histocompatibility heavy and light chains induced by viral peptides. Nature 1989 ; 340 : 443-8.

7. Vitiello A, Potter TA, Sherman LA The role of b-2 microglobulin in peptide binding by class I molecules. Science 1990 ; 250 : 1423-6.

8. Kozlowski S, Takeshita T, Boehncke WH, et al. Excess b-2 microglobulin promoting functional peptides association with purified soluble class I MHC molecules. Nature 1991 ; 349 : 74-7.

9. Silver ML, Parker KC, Wiley DC Reconstitution by MHC-restricted peptides of HLA-A2 heavy chain with b-2 microglobulin, in vitro. Nature 1991 ; 350 : 619-22.

10. Ljunggren $\mathrm{HG}$, Stam $\mathrm{N}$, Öhlen $\mathrm{C}$, et al. Empty MHC class I molecules come out in the cold. Nature $1990 ; 346$ : 476-80.

11. Rock KL, Gamble S, Rothstein L, Gramm C, Benacerraf B. Dissociation of b-2 microglobulin leads to the accumulation of a substantial pool of inactive class MHC heavy chains on the cell surface. Cell 1991 ; 65 : 611-20.

12. Pérarneau B, Siegrist CA, Gillet A Vincent C, Kimura S, Lemmonier FA b2-microglobulin restriction of antigen presentation. Nature $1990 ; 346$ : 751-6.

13. Calin-Laurens V, Forquet F, Mottez E, et al. Cytosolic targeting of hen egg lysozyme gives rise to a short-lived protein presented by class I but not class II major histocompatibility complex molecules. Eur J Immunol 1991; 21: 761-9.

14. Parham P. Half of a peptide pump. Nature 1991 ; 351 : 271-2.

15. Spies T, Bresnahan M, Bahram S, et al. A gene in the human major histocompatibility complex class II region controlling the class I antigen presentation pathway. in vitro $[8,9]$ ont permis de mieux appréhender les différentes étapes de la biosynthèse des molécules du $\mathrm{CMH}$ de classe I et permettent de proposer le modèle de maturation suivant. Après leur translocation dans le réticulum endoplasmique $\mathrm{RE}$, la chaîne lourde et la $\beta-2 \mathrm{~m}$ peuvent donner naissance, en présence de peptides, à différents complexes : (1) des complexes chaîne lourde$\beta-2 \mathrm{~m} ; \quad$ (2) des complexes chaîne lourde-peptide ; (3) des complexes chaîne lourde- $\beta-2 m$-peptide. Seuls ces derniers sont exprimés de manière stable à la surface cellulaire. En revanche, les dimères chaîne lourde$\beta-2 \mathrm{~m}$ (c'est-à-dire les molécules de classe I "vides") exprimées à la surface cellulaire sont instables à $37{ }^{\circ} \mathrm{C}$ mais stables à $26{ }^{\circ} \mathrm{C}[10]$; dans des conditions physiologiques, ils se dissocient pour donner naissance à des chaînes lourdes libres membranaires et à de la $\beta-2 \mathrm{~m}$ relâchée dans le milieu [11]. Les chaînes lourdes libres peuvent, à la surface cellulaire, lier un peptide en présence d'un grand excès de $\beta-2 \mathrm{~m}$. Toutefois, dans les conditions physiologiques, la concentration en $\beta-2 \mathrm{~m}$ dans le sérum (contrairement à celle existant dans le réticulum endoplasmique) ne permet pas cette association. Expérimentalement, l'excès de $\beta-2 \mathrm{~m}$ peut être compensé par la présence d'une $\beta-2 \mathrm{~m}$ ayant une grande affinité pour la chaîne lourde (la $\beta-2 \mathrm{~m}$ bovine par exemple). Enfin, les complexes chaîne lourde-peptide, retenus dans le réticulum endoplasmique et les chaînes lourdes libres membranaires, incapables de lier un peptide, joueraient un rôle physiologique peu important.

En conclusion, il apparaît que le réticulum endoplasmique est le compartiment cellulaire où physiologiquement se forment les complexes peptide-molécule de classe I. L'association avec la $\beta-2 \mathrm{~m}$ (et/ou le peptide ?) est une étape essentielle pour que le site de liaison au peptide des molécules de classe I soit fonctionnel, la liaison de la $\beta-2 \mathrm{~m}$ (et/ou du peptide ?) à la chaîne lourde induisant très probablement un changement de conformation du site de liaison [12]. De plus, la liaison du peptide doit induire un nouveau changement de conformation puisqu'une fois formé le complexe est très stable et aucun échange de peptide ou de $\beta-2 \mathrm{~m}$ n'est possible à la surface cellulaire. Il n'est pas exclu que des molécules chaperonnes $\left(\mathrm{m} / \mathrm{s} n^{\circ} 5\right.$, vol. $\left.7, p .496\right)$ participent à la maturation des molécules du CMH de classe I.

Différents mécanismes cellulaires sont à l'origine des peptides présents dans le réticulum endoplasmique et capables de se lier aux molécules du $\mathrm{CMH}$ de classe I. Tout d'abord l'antigène présent dans le réticulum endoplasmique peut être dégradé en peptides grâce à des mécanismes de protéolyse non identifiés. Toutefois, la translocation de l'antigène dans le réticulum endoplasmique n'est pas une étape indispensable pour sa présentation par les molécules de classe I. En effet, nous avons montré que le même peptide, qu'il provienne du lysozyme synthétisé dans le réticulum endoplasmique ou du lysozyme synthétisé dans le cytosol, peut être présenté à des cellules $\mathrm{T}$ spécifiques restreintes par les molécules de classe I [13]. Dans le cytosol sont présents de nombreux systèmes de dégradation protéolytique, des protéases à cystéine dont les calpaïnes I et II, un complexe multicatalytique de $700 \mathrm{kDa}$ organisé en protéasomes, le système de l'ubiquitine dépendant de l'ATP. Toutefois, il reste à établir si ces mécanismes interviennent dans l'apprêtement d'un antigène cytosolique et quels sont les mécanismes qui permettent le passage des peptides du cytosol vers le réticulum endoplasmique.

Des transporteurs de peptides sont probablement responsables du passage des peptides du cytosol vers le réticulum endoplasmique. En effet, de nouveaux gènes ont été identifiés dans le $\mathrm{CMH}$ et, fait surprenant, ces gènes codent pour des molécules appartenant à la superfamille des transporteurs de peptides dépendant de l'ATP [14]. Ce sont les gènes $P S F / R I N G-4$ et $R I N G$ chez l'homme $[15,16], \quad m t p$ et $m t p-1$ chez le rat [17], HAM1 et HAM2 chez la souris [18]. Les membres de cette superfamille, comme la glycoprotéine $\mathrm{P}$ responsable de la résistance multiple aux anticancéreux [19], sont organisés en deux monomères symétriques, chacun d'eux contenant un site de liaison à l'ATP et six régions 
hydrophobes transmembranaires. La participation de ces gènes dans la présentation de peptides par les molécules du CMH de classe I repose sur l'utilisation de cellules humaines mutantes exprimant peu de molécules de classe I dans les conditions physiologiques. L'expression membranaire des molécules de classe I peut être induite soit après incubation des cellules mutantes avec des peptides capables de se lier aux molécules de classe I, soit après transfection de ces cellules par un vecteur d'expression recombinant contenant l'ADNc codant pour le PSF [20]. Toutefois la preuve directe de l'existence de transporteurs de peptides impliqués dans l'apprêtement de l'antigène reste à établir.

\section{Formation des complexes peptide-CMH de classe II}

Les molécules de classe II ne sont exprimées que sur certaines cellules telles que les cellules B, les cellules $T$ activées humaines, les macrophages, les cellules de Langerhans, les cellules interdigitantes et les cellules épithéliales thymiques. Les molécules de classe II sont formées de deux chaînes polymorphes $\alpha$ et $\beta$ de 34 et de $28 \mathrm{kDa}$. Les études de modélisation moléculaire suggèrent que la structure tridimensionnelle des molécules de classe II est similaire à celle des molécules de classe I. La chaîne invariante, notée Ii, est une chaîne monomorphe qui s'associe de façon transitoire et non covalente aux dimères $\alpha \beta$ en cours de biosynthèse. La chaîne invariante peut subir de nombreuses modifications posttraductionnelles donnant naissance à toute une famille de protéines.

Les chaînes $\alpha$ et $\beta$ des molécules de classe II synthétisées au niveau du réticulum endoplasmique s'associent rapidement à la chaîne $\mathrm{Ii}$, présente en excès dans ce compartiment. Les molécules de classe II, contrairement à celles de classe I, ne vont pas directement à la membrane (trois heures leur sont nécessaires pour atteindre la membrane) mais croisent la voie endocytique [21]. Cette voie de biosynthèse particulière est une caractéristique intrinsèque des molécules de classe II et est indépendante de la présence de la chaîne Ii. Les trimè$\mathrm{m} / \mathrm{s} n^{\circ} 7$, vol. 7, seplembre 91

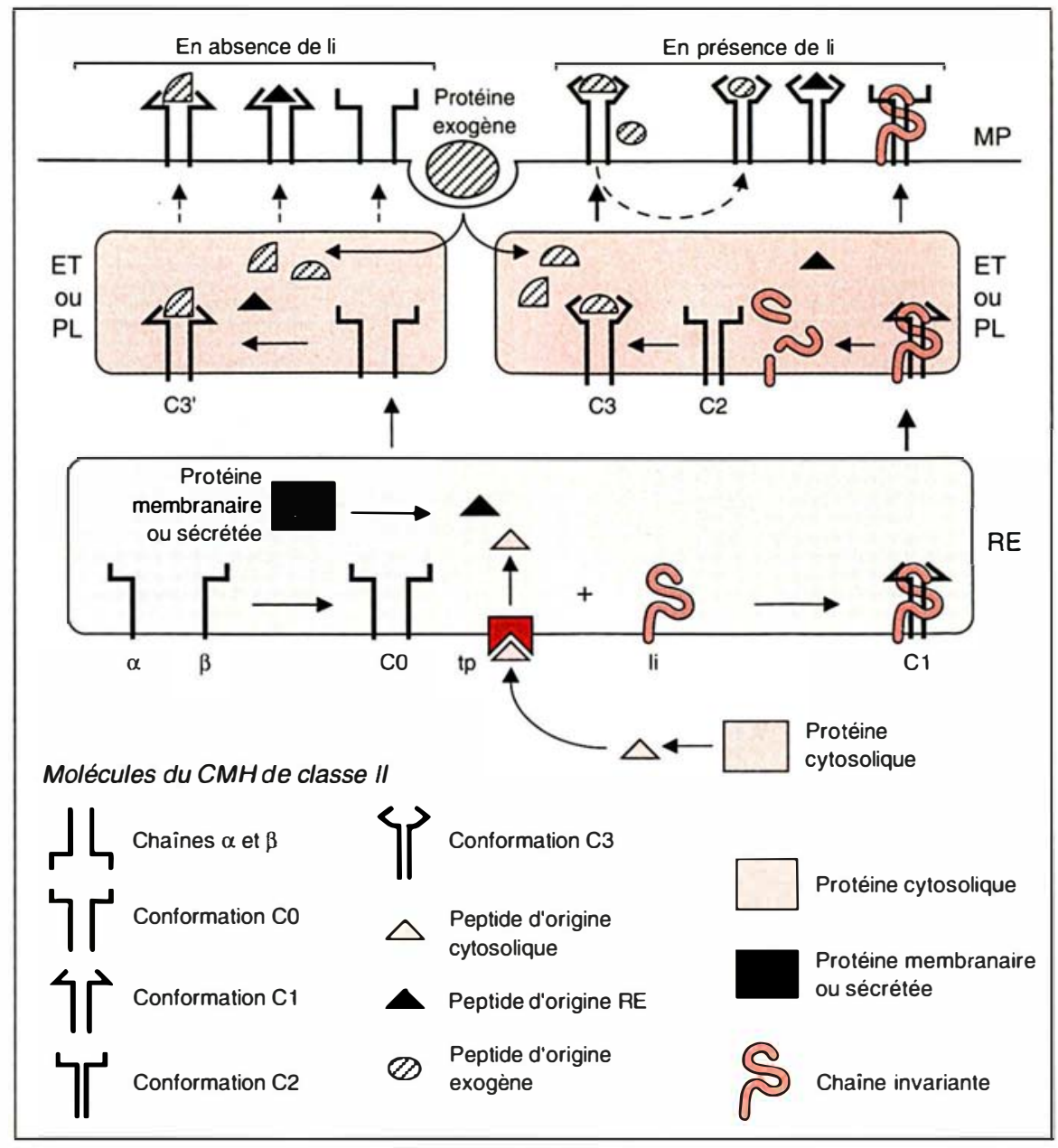

Figure 2. Schéma de la biosynthèse des molécules du CMH de classe II. Les chaînes $\alpha$ et $\beta$ des molécules du CMH de classe II s'associeraient très vite dans le réticulum endoplasmique (RE) pour former un complexe transitoire $\alpha / \beta$ de conformation $\mathrm{CO}$ ayant peu d'affinité pour les peptides d'origine endogène (triangles) présents dans ce compartiment. La chaîne invariante (li) étant physiologiquement exprimée en excès par rapport aux chaînes $\alpha$ et $\beta$, ce dimère $\alpha / \beta$ de conformation $\mathrm{CO}$ s'associerait très rapidement à li pour donner une nouvelle conformation C1 ayant elle aussi peu d'affinité pour les peptides. L'affinité du complexe pour les peptides ne serait acquise que lorsque le complexe $\alpha / \beta / l i$ atteint le compartiment acide de type endosome tardif (ET) ou prélysosome (PL) contenant les peptides dérivés de l'antigène exogène (ellipse) qui a été intégré par endocytose. Dans ce compartiment, li se dissocie des molécules de classe II par dégradation protéolytique, ce qui permettrait aux dimères $\alpha / \beta$ d'acquérir une conformation $C 2$ de haute affinité pour les peptides présents dans ce compartiment d'origine exogène (ellipses ou portions d'ellipse) mais également d'origine endogène (triangles). Ce complexe classe II-peptide (forme C3) migrerait enfin à la surface cellulaire. Le peptide associé à la molécule du CMH pourrait éventuellement être échangé avec un autre peptide exogène après recyclage du complexe. Un faible pourcentage des molécules de classe Il exprimées à la surface cellulaire restent associées à li. En absence de chaîne invariante, c'est-à-dire dans des conditions non physiologiques, seule la forme CO pourrait atteindre l'endosome tardif. II reste à étabir si ces formes lient un peptide et/ou si elles migrent à la membrane cellulaire. Les complexes classe II/peptide ainsi obtenus auraient une conformation $C^{\prime} 3$ différente de C3. Cette différence serait soit quantitative (I'affinité pour le peptide serait différente), soit qualitative (le peptide fixé serait différent). 


\section{RÉFÉRENCES}

16. Trowsdale J, Hanson I, Mockridge I, Beck S, Townsend A, Kelly A. Sequences encoded in the class II region of the MHC related to the " $A B C$ " superfamily of transporters. Nature $1990 ; 348: 741-3$.

17. Deverson EV, Gow IR, Coadwell J Monaco JJ, Butcher GW, Howard JC. MHC class II region encoding proteins related to the multidrug resistance family of transmembrane transporters. Nature 1990 348: $735-41$.

18. Monaco JJ, Cho S, Attaya M. Transport protein genes in the murine MHC : possible implications for antigen processing Science 1990 ; 250 : 1723-6.

19. Marie JP.Le phénomène de résistance multiple aux anticancéreux: les gènes MDR et la P-gp. médecine/sciences 1990 ; 6 : 443-9.

20. Spies T, DeMars R. Restored expression of histocompatibility class I molecules by gene transfer of a putative peptide transporter. Nature 1991 ; 351 : 323-4.

21. Neefjes JJ, Stollorz V, Peters PJ, Geuze HJ, Ploegh HL. The biosynthetic pathway of MHC class II but not class I molecules intersects the endocytic route. Cell $1990 ; 61$ : 171-83.

22. Roche PA, Cresswell $P$. Invariant chain association with HLA-DR molecules inhibits immunogenic peptide binding. Nature $1990 ; 345: 615-8$.

23. Peters PJ, Neefjes JJ, Oorschot V, Ploegh HL, Geuze HJ. Segregation of MHC class II molecules from MHC class I molecules in the Golgi complex for transport to lysosomal compartments. Nature $1991 ; 349$ : 669-76. res $\alpha \beta$ Ii formés dans le réticulum endoplasmique ne posséderaient pas une conformation favorable à la fixation de peptides [22]. Au niveau du réseau transgolgien (RTG), les trimères $\alpha \beta$ Ii migrent vers des vésicules de type lysosomal (pré-lysosomes ?), où ils semblent s'accumuler [23], et/ou vers un compartiment endosomique tardif [24, 25]. Avant leur migration à la membrane cellulaire, la chaîne Ii se dissocie des dimères $\alpha \beta$ par protéolyse, vraisemblablement dans un compartiment cellulaire de type prélysosomal et/ou endosomal tardif. Ce compartiment cellulaire est certainement primordial pour la présentation de l'antigène par les molécules de classe II car c'est dans ce compartiment qu'interviendrait, outre la dissociation Ii/molécule de classe II, la dégradation de l'antigène endocyté par la CPAg, et l'association entre le peptide et la molécule de classe II.

L'association transitoire $\mathrm{du}$ dimère $\alpha \beta$ avec la chaîne Ii semble une étape indispensable pour obtenir des molécules de classe II fonctionnelles, c'est-à-dire capables de lier un peptide. En effet, nous avons montré qu'il existe une corrélation entre le taux d'expression de la chaîne Ii et la capacité des CPAg à présenter le lysozyme de poule à des hybridomes $\mathrm{T}$ spécifiques dont l'activité est restreinte par les molécules du $\mathrm{CMH}$ de classe II. Dans notre modèle, Ii favorise aussi bien la présentation du lysozyme apporté de façon externe à la CPAg (antigène exogène) que celle du lysozyme synthétisé et sécrété par la CPAg (antigène endogène) [26]. L'ensemble des résultats expérimentaux suggère que, au cours de leur maturation, les molécules de classe II subissent des changements de conformation. Nous proposons que dans le réticulum endoplasmique le passage du dimère $\alpha \beta$ au trimère $\alpha \beta \mathrm{Ii}$ s'accompagne d'un premier changement de conformation des molécules du $\mathrm{CMH}$ de classe II (passage de la forme $\mathrm{C} 0$ à la forme C1). Le passage de C1 à C2 résulterait de la protéolyse de la chaîne Ii et le passage de C2 à C3 de la liaison des peptides sur les formes C2. Nous proposons que seule la forme $\mathrm{C} 2$ possède une grande affinité pour des peptides et que seule la forme $\mathrm{C} 3$ est exprimée de manière stable à la surface cellulaire. En absence de Ii, les molécules de classe II ne pourraient pas acquérir la conformation $\mathrm{C} 2$ et resteraient donc sous la forme $\mathrm{C} 0$, forme peu stable et peu favorable à la liaison de peptides. Toutefois, en présence d'un excès de peptides (ou de peptides se liant avec une très haute affinité), la liaison avec le peptide pourrait avoir lieu et donner naissance à des formes membranaires C3' (instables?).

\section{Caractéristiques}

\section{des peptides antigéniques}

Pour être reconnu par un lymphocyte $T$, un peptide doit être capable d'interagir à la fois avec une molécule du CMH et un TcR. Selon la nomenclature consacrée, nous appellerons agrétope l'ensemble des résidus impliqués dans la liaison avec la molécule du $\mathrm{CMH}$ et épitope l'ensemble des résidus impliqués dans la liaison avec le TcR.

La nature exacte des peptides présentés reste à définir car, à ce jour, seuls quatre peptides de huit à dix résidus ont pu être isolés à partir de complexes peptide-CMH de classe II ou de classe I. De plus, les peptides capables de se lier à une molécule du $\mathrm{CMH}$ dans la CPAg semblent être protégés d'une dégradation complète [27]. L'utilisation de peptides synthétiques a permis de déterminer leur affinité pour les molécules du $\mathrm{CMH}$ dans des conditions qui sont néanmoins très éloignées de celles existant dans le réticulum endoplasmique ou dans les endosomes. Les constantes de dissociation varient de $6.10^{-4} \mathrm{M}$ pour des molécules solubilisées de classe I [28] à $10^{-6} \mathrm{M}$ pour des molécules solubilisées de classe II. Une affinité plus grande ( $\mathrm{Kd}$ de $\left.10^{-9} \mathrm{M}\right)$ a été déterminée à partir de peptides radiomarqués et de molécules de classe II exprimées sur des cellules B humaines vivantes [29]. Cette faible affinité des peptides pour les molécules du $\mathrm{CMH}$ implique que la concentration des peptides, dans les compartiments contenant les molécules du $\mathrm{CMH}$, doit être suffisamment grande pour que des complexes peptide-molécule du $\mathrm{CMH}$ puissent se former. Les molécules du $\mathrm{CMH}$ sont donc des récepteurs de peptides, saturables et capables de 
lier avec une affinité faible un grand nombre de peptides différents en utilisant un seul site de fixation. La faible affinité des peptides pour les molécules du CMH peut être due au faible nombre de résidus qui établissent le contact entre le peptide et la molécule du CMH. Bien que fonctionnelle, la spécificité de cette liaison est "floue", puisqu'une même molécule du $\mathrm{CMH}$ peut fixer plusieurs peptides et qu'un même peptide peut se lier à des molécules du $\mathrm{CMH}$ de nature différente (d'haplotype différent ou de classe différente). Seules des études exhaustives permettront de comprendre la base moléculaire de cette spécificité et donc de prédire, pour une molécule du CMH et un peptide donné, l'agrétope. La prédiction d'épitopes $\mathrm{T}$ présents dans une protéine est, à l'heure actuelle, impossible. En effet, il reste à définir : (1) si parmi toutes les conformations que peut adopter un peptide, une ou plusieurs sont capables de se loger dans la niche de la molécule du $\mathrm{CMH}$; (2) si, après sa liaison à la molécule du CMH, le peptide conserve sa conformation initiale (hélice $\alpha$, brin $\beta$, hélice 310 ) ou s'il subit un changement conformationnel induit ; enfin, si un complexe peptide-CMH donné est reconnu par un seul type de TcR ou par différents TcR (c'està-dire par différentes cellules $\mathrm{T}$ ), chacun "voyant " la conformation finale $\mathrm{du}$ complexe peptide-molécule du $\mathrm{CMH}$ sous un angle différent.

\section{Reconnaissance du complexe par le TcR}

Bien que les lymphocytes $T$ puissent exprimer deux types de TcR différents, $\alpha \beta$ ou $\gamma \delta$, seul le TcR $\alpha \beta$ semble être impliqué dans la reconnaissance du complexe peptidemolécule du $\mathrm{CMH}$ de classe I ou de classe II. Au cours de ces dernières années, le rôle du polymorphisme du $\mathrm{CMH}$ a été réinterprété [30]. En effet, la structure cristallographique des molécules de classe I montre que les résidus polymorphes, dans leur grande majorité, pointent vers la niche à peptides et ne sont donc en position d'établir des contacts qu'avec le peptide présenté. Il a donc été proposé que le polymorphisme $\mathrm{m} / \mathrm{s} n^{\circ} 7$, vol. 7 , seplembre 91 des molécules du $\mathrm{CMH}$ interviendrait, non pas au niveau de la reconnaissance par le $\mathrm{TcR}$, mais dans la sélection des peptides dérivés de l'antigène. La reconnaissance de résidus monomorphes du CMH permettrait de stabiliser l'interaction entre le $\mathrm{TcR}$ et le complexe peptidemolécule du CMH. La modélisation de la reconnaissance par le TcR d'un complexe [31, 32] peptide-molécule de classe I montre que seuls les résidus appartenant à la région la plus variable (équivalente à la troisième boucle hypervariable ou CDR3 des Ig) des chaînes $\alpha$ et $\beta$ du TcR interagissent avec le peptide présenté. Les régions du TcR analogues aux régions CDR1 et CDR2 des Ig interagissent avec la face externe des deux hélices $\alpha$ des molécules du $\mathrm{CMH}$, région où il existe très peu de résidus polymorphes. Alors que certains résultats expérimentaux corroborent cette hypothèse, d'autres suggèrent que des résidus appartenant aux trois régions hypervariables du TcR pourraient interagir avec le peptide. (Nicolas Glaichenhaus, communication personnelle).

\section{L'apprêtement est un mécanisme cellulaire général}

Dans une CPAg, tout constituant protéique endogène, qu'il appartienne au "soi " ou au "non-soi ", est soumis à un renouvellement permanent et est donc une source importante de peptides susceptibles de se lier aux molécules du $\mathrm{CMH}$ [33], l'association avec les molécules de classe I ayant lieu dans le réticulum endoplasmique et celle avec les molécules de classe II dans les endosomes. La présentation de complexes peptide du soi-molécule du $\mathrm{CMH}$ joue un rôle primordial au cours de l'ontogénie des lymphocytes T dans le thymus. D'une part, elle conduit à l'élimination fonctionnelle (par délétion clonale et/ou anergie) des lymphocytes $T$ reconnaissant les peptides du soi associés à une molécule du $\mathrm{CMH}$ de classe I ou de classe II ; de ce fait, les lymphocytes $\mathrm{T}$ matures qui migrent vers la périphérie sont "tolérants au soi ". D'autre part, elle module le répertoire des lymphocytes $\mathrm{T}$ matures car elle permet de sélectionner les lymphocytes $\mathrm{T}$ qui, à la périphérie, reconnaîtront un peptide étranger à condition que celui-ci soit associé à une molécule du $\mathrm{CMH}$ identique à celle exprimée dans le thymus. Enfin, des peptides dérivés des régions variables des anticorps et des $T c R$ doivent être présentés par les molécules du $\mathrm{CMH}$ et reconnus par certains lymphocytes $\mathrm{T}[33,34]$. Ces idiopeptides, spécifiques d'un clone lymphocytaire, joueraient un rôle important dans la régulation des réponses immunitaires $\mathrm{T}$ dépendantes en permettant des interactions $\mathrm{T}$ - $\mathrm{B}$ ou T-T. Expérimentalement, seuls des idiopeptides dérivés d'anticorps et associés à des molécules de classe II ont été décrits à ce jour [35].

\section{Conclusion}

La compilation des résultats expérimentaux montre que le lieu où s'effectue la dégradation de l'antigène, qu'il appartienne au " soi " ou au " non-soi ", gouverne l'association préférentielle des peptides produits aux molécules de classe I ou de classe II du CMH. En effet, un peptide présent dans le réticulum endoplasmique se lie principalement à une molécule de classe I ; par contre un peptide présent dans les endosomes se lie uniquement à une molécule de classe II. Cette dichotomie est le reflet de la différence qui existe entre la biosynthèse des molécules du $\mathrm{CMH}$ de classe I et de classe II.

Cette compréhension des mécanismes de l'apprêtement de l'antigène conduit à proposer de nouvelles stratégies vaccinales. Pour induire la synthèse d'anticorps neutralisants, un vaccin synthétique devra, d'une part, comprendre un épitope B (déterminant antigénique reconnu par un anticorps) et, pour stimuler des cellules $\mathrm{T}$ helper $\mathrm{CD}^{+}{ }^{+}$, un peptide capable de s'associer à des molécules du CMH de classe II et, d'autre part, assurer le ciblage de ces peptides vers les endosomes. De même, pour induire la formation de cellules T CD8 + cytolytiques protectrices, il faudra concevoir un vaccin comportant un peptide capable de s'associer aux molécules de classe I et permettant le ciblage de celui-ci vers le cytosol ou le réticulum endoplasmique. 
Dans tous les cas, il reste à définir les agrétopes universels que devront contenir les peptides pour qu'ils se lient à au moins une molécule du $\mathrm{CMH}$ de n'importe quel individu

\section{RÉFÉRENCES}

24. Bakke O, Dobberstein B. MHC class II-associated invariant chain contains a sorting signal for endosomal compartments. Cell 1990 ; 63 : 707-16.

25. Lotteau V, Teyton L, Peleraux A, et al. Intracellular transport of class II MHC molecules directed by invariant chain. Nature $1990 ; 348: 600-8$.

26. Bertolino $P$, Forquet F, Pont S, Koch N, Gerlier D, Rabourdin-Combe C. Correlation between invariant chain expression level and capability to present antigen to MHC class II restricted T-cells. Int Immunol 1991; 3: 435-43.

27. Falk K, Rötzschke O, Rammensee HG Cellular peptide composition governed by major histocompatibility complex class I molecules. Nature 1990 ; 348 : 248-51.

28. Bouillot M, Choppin J, Cornille F, et al. Physical association between MHC class I molecules and immunogenic peptides. Nature 1989 ; 339 : 473-5.

29. Busch R, Rothbard JB. Detection of peptide-MHC class II complexes on the surface of intact cells. J Immunol Methods 1990 ; $134: 1-22$.

30. Kourilsky P, Claverie JM. MHCantigen interaction: what does the T-cell receptor see? Adv Immunol 1989; 45: 107-93.

31. David MM, Bjorkman P. T-cell antigen receptor gene and $T$-cell recognition Nature 1988 ; 334 : 395-402.

32. Claverie JM, Prochnicka-Chalufour A, Bougueleret L. Immunological implications of a Fab-like structure for the T-cell receptor. Immunol Today $1989 ; 10: 10-4$.

33. Kourilsky P, Chaouat G, RabourdinCombe C, Claverie JM. Working principles in the immune system implied by the "Peptidic Self " model. Proc Nall Acad Sci USA $1987 ; 84: 3400-4$.

34. Leserman $\mathrm{L}$. The introversion of the immune response : a hypothesis for T-B interaction. Immunol Today $1985 ; 6: 352-5$.

35. Yurin VL, Rudensky AY, Mazel SM, Blechman JM. Immunoglobulin-specific T-B cell interaction. II. T-cell clones recognize the processed form of B cell'own surface immunoglobulin in the context of the major histocompatibility complex class II molecule. Eur J Immunol $1989 ; 19$ : 1685-91.

\section{Summary}

Molecular biology of antigen presentation

Antigen-specific $\mathrm{T}$ cells recognize, via their TcR, a bimolecular complex associating an antigen frag. ment and a Major Histocompatibility Complex (MHC) class I or class II molecule. Recent data have provided a relationship between antigen presentation, antigen degradation and the biosynthesis pathways of MHC molecules. We present our current view of the molecular steps of the antigen processing by an antigen-presenting cell (APC) : proteolysis of self or non-self antigen into peptides, maturation of functional peptide carriers, namely the MHC molecule, colocalization of peptides and MHC molecules into the same intracellular compartment and presentation of the peptide-MHC complexes to $\mathrm{MHC}$ class I or class II restricted $\mathrm{T}$ cells. As a consequence, $\mathrm{MHC}$ polymorphism is now understood as a means to enlarge the pool of $\mathrm{MHC}$ binding peptides since polymorphic residucs govern the selection of bound peptide. Accordingly during $\mathrm{T}$ cell recognition both bound peptide and monomorphic MHC residues are likely to interact with $\mathrm{T}$ cell receptor.

\section{TIRÉS A PART}

C. Rabourdin-Combe 